\title{
Dos géneros y tres especies nuevos de Penicillophorinae (Coleoptera: Phengodidae) de México
}

\author{
Two new genera and three new species of Penicillophorinae (Coleoptera: Phengodidae) of \\ Mexico
}

Santiago Zaragoza-Caballero

Colección Nacional de Insectos, Departamento de Zoología, Instituto de Biología, Universidad Nacional Autónoma de México. Apartado postal 70153, 04510 México, D. F. México.

Correspondencia: zaragoza@ibiologia.unam.mx

\begin{abstract}
Resumen. Se describen e ilustran 2 géneros y 3 especies nuevos de Phengodidae: Penicillophorinae, procedentes de Ixtlahuacán, Colima y Huatulco y Santiago Dominguillo, Oaxaca. Los géneros y especies son: Walterius caballeroae, n. sp., W. emilioi n. sp. y Tarsakanthos minuta n. sp. Se elabora una clave para la identificación de los 5 géneros conocidos de Penicillophorinae.
\end{abstract}

Palabras clave: Coleoptera, Phengodidae, Penicillophorinae, Walterius n. gen., Tarsakanthos n. gen. n. sp., México.

\begin{abstract}
Two new genera and 3 new species of Phengodidae: Penicillophorinae, are described and illustrated. They were colleted in Ixtlahuacán, Colima, Huatulco, Oaxaca and Santiago Dominguillo, Oaxaca. These genera and new species are: Walterius caballeroae, n. sp. W. emilioi n. sp. and Tarsakanthos minuta n. sp. Key for of the 5 known genera of Penicillophorinae is presented.
\end{abstract}

Key words: Coleoptera, Phengodidae, Penicillophorinae, Walterius n. gen., Tarsakanthos n. gen. n. sp., Mexico.

\section{Introducción}

En el marco de un proyecto sobre insectos asociados al bosque tropical caducifolio, encontramos ejemplares de Phengodidae (Coleoptera) procedentes del estado de Oaxaca y de Colima que identificamos como pertenecientes de la subfamilia Penicillophorinae, la cual se caracteriza por presentar las antenas serradas y sedas en los 2 primeros segmentos abdominales como reconoce Paulus (1975) en Penicillophorus. Wittmer (1976, 1981) incorpora a esta subfamilia, los géneros Adrendocera y Acladocera que presentan las antenas serradas y espinas que forman peines ventrales en el primer tarsómero del pro y mesotarso de Adrendocera y la ausencia de peines en Acladocera.

Los individuos que se proponen como integrantes de un nuevo género, al igual que los descritos por Wittmer no tienen los mechones de sedas en los primeros segmentos abdominales; sin embargo, las antenas serradas y las espinas formando peines en los tarsos sí están presentes. En Phengodinae y Mastinocerinae (Phengodidae) las antenas son birramosas y los peines tarsales pueden o no estar presentes.

Recibido: 10 agosto 2007; aceptado: 08 enero 2008
Se elaboró una clave para identificar los ahora 5 géneros conocidos de Penicillophorinae considerando el número de artejos antenales y otras características.

\section{Material y métodos}

Los 5 ejemplares estudiados proceden del biotopo conocido como bosque tropical caducifolio. Las localidades donde fueron recolectados son: Santiago Dominguillo, Oaxaca, región localizada en la zona de La Cañada; Huatulco, Oaxaca, ubicada en las estribaciones de la región Sierra Sur y Costa de Oaxaca; Ixtlahuacán, Colima, región que corresponde al sistema montañoso Sierra de Manantlán.

Los ejemplares se capturaron en trampas de intercepción tipo Malaise o bien cayeron al embudo al ser atraídos a la luz y recolectados en contenedores con alcohol al 70\%, y separados para su montaje en triángulos de cartulina o sobre laminillas de vidrio incluidas en bálsamo de Canadá. Previamente fueron disectadas para separar alas membranosas y aparato reproductor.

Con el auxilio de una cámara clara adaptada a un microscopio Olympus SZH10, se elaboraron los esquemas 
correspondientes a un aumento de 140X. Las medidas se tomaron con una reglilla milimétrica y se expresan en milímetros

\section{Descripción}

Walterius n.gen.

Especie tipo: Walterius caballeroae

Diagnosis y comentarios. Walterius n. gen. Antenas con 12 antenómeros; palpos maxilares con 4 palpómeros; primer tarsómero del pro y mesotarso con un peine ventral a todo lo largo; segundo tarsómero del mesotarso tan largo como el primero. Relacionado con Acladocera Wittmer por presentar 2 fositas tentoriales. Lo separa las antenas con 11 antenómeros; palpos maxilares con 3 palpómeros; tarsos simples, sin peines; segundo tarsómero del mesotarso 2 veces más largo que el primero.

Descripción del genotipo. Cabeza. Larga, tan ancha como el pronoto; prominencias antenales poco aparentes; distancia interantenal más corta que la mitad del primer antenómero; ojos medianos, granulosamente facetados; antenas filiformes, formadas por 12 antenómeros; clípeo indistinto; labro membranoso mandíbulas dentadas; palpos maxilares de 4 palpómeros, el último ovoide, galea setífera; palpos labiales de 2 palpómeros; tentorio con 2 fositas, un poco separadas. Tórax. Pronoto convexo, con el borde posterior continuo, ligeramente más angosto que los élitros; élitros con el borde posterior redondo; alas membranosas con la célula radial abierta; primer tarsómero de las patas anteriores y medias con un peine ventral completo; uñas simples.

Etimología. El nombre de Walterius es en honor del Dr. Walter Wittmer quien dedicó gran parte de su vida al estudio de la familia Phengodidae.

\section{Walterius caballeroae n. sp. (Figs. 1-2)}

Diagnosis de la especie tipo. Largo total 2.7. Ancho total 0.6. Cuerpo pardo, alargado; tegumento de la cabeza brillante setígero, antenas casi moniliformes; último palpómero maxilar ovoide; palpos labiales con 2 palpómeros; abdomen con 7 ventritos.

El color, forma de las antenas, forma del último palpómero maxilar, número de palpómeros labiales y número de ventritos abdominales, separa $W$. caballeroae de W. emilioi.

Descripción del holotipo macho. Cabeza. Ligeramente más larga que ancha (0.44 - 0.37) a nivel de los ojos (Fig. 1), distancia interantenal 0.1 ; antenas sobrepasando el pronoto, tercer antenómero más corto que el segundo y el cuarto; del cuarto al decimoprimero semejantes, la longitud de los antenómeros 4-6 es de 0.24; ojos medianos, semiesféricos, ocupando casi la quinta parte del ancho de la cabeza (Fig. 1), más largos que anchos, (0.16-0.08); distancia interocular 0.22 ; frente vertical, con el borde anterior ligeramente cóncavo, tan ancha como el largo del primer antenómero; clípeo indistinto; labro membranoso; mandíbulas falcadas; palpos maxilares con 4 palpómeros, el último robusto, más largo que los 3 primeros juntos; galea setífera; palpos labiales de 2 palpómeros; gula con una sutura en forma de "Y" (Fig. 2). Tórax. Pronoto ligeramente más largo que ancho (0.44-0.40), bordes laterales casi paralelos, el anterior casi recto, el posterior continuo y convexo; escutelo ligeramente punteado y setífero; élitros cortos, apenas sobrepasando las coxas posteriores, 4 veces más largos que anchos (0.88-0.22), casi paralelos, ápice romo, tegumento brillante, chagrinado en su tercio distal, el resto espaciadamente punteado y setífero (Fig. 1), epipleura ancha; alas membranosas largas cubriendo todo el abdomen, venación reducida, sin vena radial, célula radial abierta; prosterno ancho, con el borde posterior convexo, mesosterno largo, metasterno casi tan largo como el mesosterno; patas cortas aplanadas tibias con espinas apicales, primer tarsómero del metatarso ligeramente más largo que el segundo, uñas simples. Abdomen. Con 7 ventritos visibles, el sexto con el borde posterior cóncavo, ápice del séptimo emarginado (Fig. 2); edeago robusto, con el ápice de los lóbulos laterales dentado (Fig. 2). Hembra desconocida.

Holotipo macho. México, Colima, Ixtlahuacán, Trampa Malaise $415^{\circ} 48^{\prime} 54.1$ ' $\mathrm{N}$; 96 $16^{\circ}$ ' 28.6', O; $179 \mathrm{~m}$, 27.IX. 2006 y12.X.2006. Cols. Felipe Noguera, Santiago Zaragoza, Enrique González, Enrique Ramírez, Lucía Salas.

Etimología. El nombre caballeroae es en recuerdo de mi madre Guadalupe Caballero.

Walterius emilioi $\mathrm{n}$. sp. (Figs. 3-10)

Diagnosis. Largo total 2.5. Ancho total 0.6. Cuerpo alargado, ambarino a excepción de las patas, del borde posterior de los segmentos abdominales y del aparato reproductor de color más claro; tegumento de la cabeza brillante, gruesamente punteado, setígero; antenas un tanto serradas; último palpómero maxilar securiforme; palpos labiales con 3 palpómeros; abdomen con 8 ventritos visibles.

El color, ornamento de la cabeza, forma de las antenas, forma del último palpómero maxilar, número de palpómeros labiales y número ventritos abdominales visibles, separa a $W$. eminlioi de $W$. caballeroae.

Descripción del holotipo macho. Cabeza. Casi tan ancha como larga (0.38-0.40) a nivel de los ojos (Fig. 3); tegumento brillante granulosamente punteado; vértex 


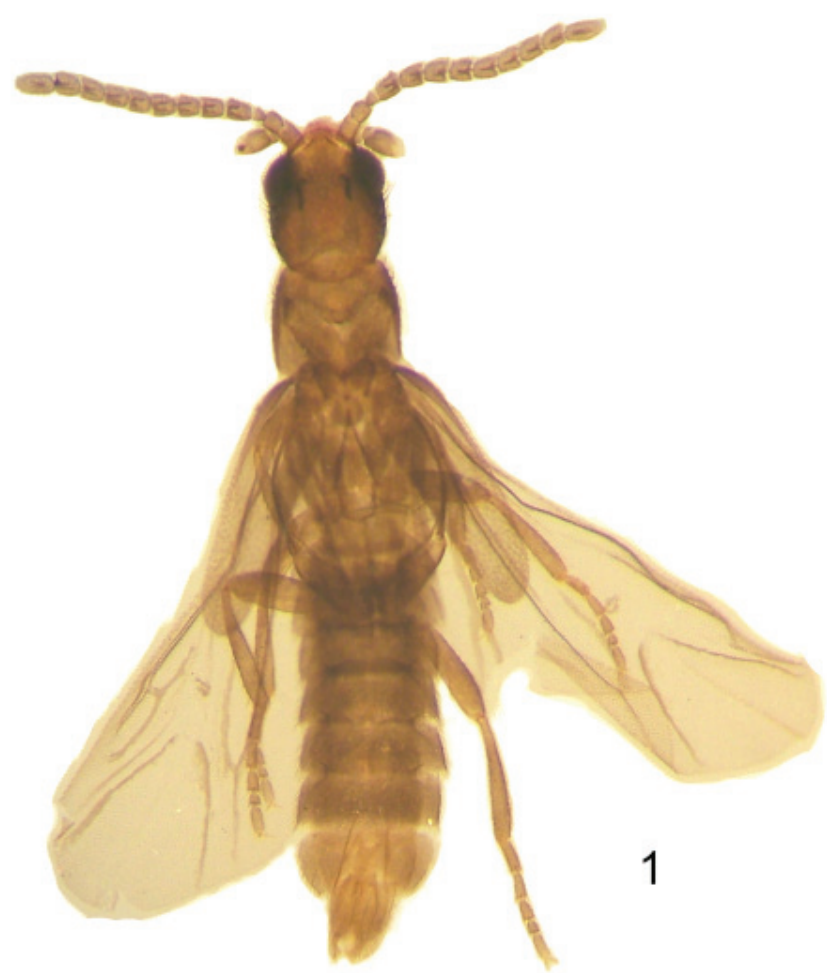

Figuras. 1-2. Walterius caballeroae n. sp., vista dorsal y ventral.

abombado; tubérculos anteníferos separados en su base; distancia interantenal 0.03; antenas cortas, serradas, casi filiformes, un tanto comprimidas, tercer antenómero más corto que los siguientes; longitud de los antenómeros 46 de 0.25 ; ojos granulosamente facetados, semiesféricos, medianos, ocupando dorsalmente la cuarta parte de la cabeza y un tercio por su parte ventral (Fig. 3); distancia interocular 0.21; frente vertical, un poco más angosta que el largo del primer antenómero, borde anterior cóncavo; clípeo indistinto; labro membranoso, borde anterior lobulado, mandíbulas falcadas, anchas, robustas, con un pequeño diente en su parte basal; palpos maxilares de 4 palpómeros, último ovoide, securiforme, tan largo como los 3 anteriores juntos, galea angosta y setífera; palpos labiales de 3 palpómeros, el último truncado; gula con una sutura en forma de "Y" (Fig. 4). Tórax. Pronoto. Ligeramente más largo que ancho (0.50. - 0.48.) (Fig. 3), más ancho hacia la parte media, ligeramente excavado, con una quilla longitudinal media, ángulos posteriores redondeados, borde anterior casi recto, el posterior continuo, tegumento chagrinado, brillante, espaciadamente punteado y setífero; escutelo ojival, élitros un tanto paralelos, ápice romo, cortos, apenas sobrepasando el tercer par de coxas, 3 veces más largos que anchos (0.86-0.28), epilpleura ancha sólo en la mitad anterior, tegumento rugosa,

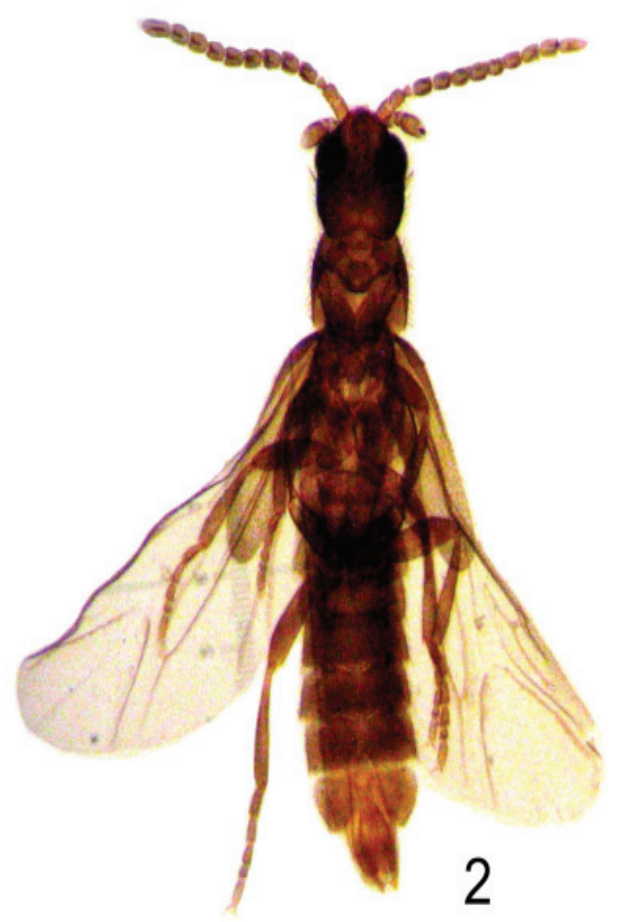

gruesa y estrechamente punteado, vestidura setífera; alas membranosas largas (Fig. 5), cubriendo casi todo el abdomen, venación tipo lampiroide: con la célula radial abierta (CR), la mediana posterior (MP) unida a la radial posterior (RP), se reconocen también la mediana posterior 4 (MP4) que se une a la cubital-anal 1 (CuA1), están también presentes la cubital-anal 2 (CuA2), la cubital-anal $3(\mathrm{CuA} 3)$ y la anal posterior $3+4(\mathrm{AP} 3+4)$; patas cortas, protibias con espinas apicales, primer tarsómero del pro y mesotarso con un peine ventral a todo lo largo (Figs. 6-7), segundo tarsómero del pro y mesotarso tan largo como el primero, el quinto cilíndrico, tan largo como el primero, uñas simples. Abdomen. Con 8 ventritos visibles, borde posterior del séptimo excavado, borde posterior del octavo emarginado; edeago (Figs. 8-10) robusto, lóbulos laterales anchos, con el ápice dentado, lóbulo medio cilíndrico, curvo, con el ápice romo, saco interno largo y aplanado. Hembra desconocida.

Holotipo macho. México, Oaxaca. Entronque Carretera Salina Cruz-Santa Cruz Huatulco, 15 48'33', N; 96 $10^{\prime} 117^{\prime}$ ' O. Altitud 240 m snm., Recolectado en trampa Malaise 06-11.VII.2005; Cols. S. Zaragoza, F. Noguera, E. González, E. Ramírez. Paratipo macho. México Oaxaca. Santiago Dominguillo, 17³8'907' ' N, 96 54'703' O. Altitud $760 \mathrm{msnm}$., recolectado en trampa de atracción 

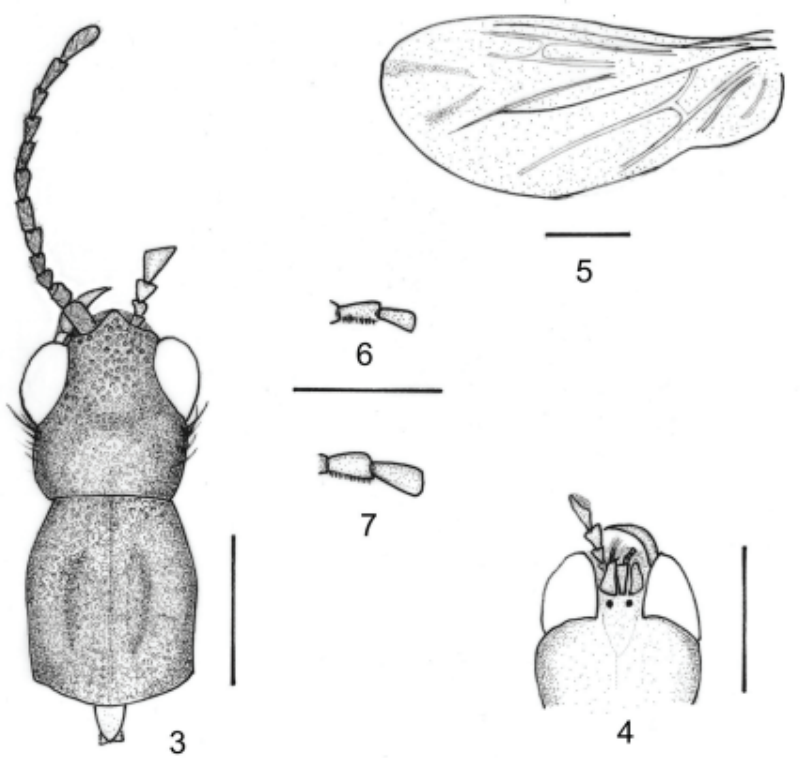

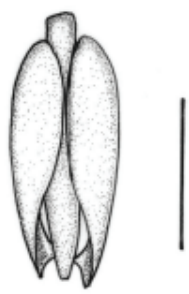

8

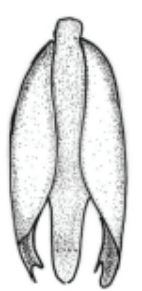

9

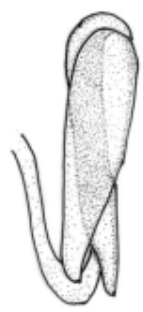

10
Figuras. 3-10. Walterius emilioi n. sp. 3, vista dorsal de la cabeza y pronoto; 4, vista ventral de la cabeza; 5 , vista dorsal del ala izquierda; 6-7, vista lateral de los primeros tarsómeros del pro y mesotarso; 8-10, vista dorsal, ventral y lateral del edeago. Línea $=0.5 \mathrm{~mm}$.

luminosa 21. I.1998, Paratipo macho misma localidad y trampa 21. VI. 1998. Cols. S. Zaragoza, F. Noguera, E. González, E. Ramírez. Los ejemplares están depositados en la Colección Nacional de Insectos (CNIN) del Instituto de Biología de la Universidad Nacional Autónoma de México.

Etimología. El nombre emilioe es en memoria de mi padre Emilio Zaragoza.

Tarsakanthos n. gen.

Especie tipo: Tarsakanthos minuta n. sp.

Diagnosis y comentarios. Tarsakanthos n. gen., Primer tarsómero de las patas anteriores con espinas largas y curvadas; palpos maxilares con 3 palpómeros, el apical acuminado; pronoto más ancho que largo; alas membranosas con la célula radial cerrada. Se relaciona con Adendrocera Wittmer por tener las antenas formadas por 11 antenómeros, presentar 1 fosita tentorial y en el largo semejante del primer tarsómero del pro y mesotarso.

Descripción del genotipo. Cabeza. Corta, tan ancha como el pronoto; prominencias antenales pronunciadas; distancia interantenal tan larga como el primer antenómero; ojos grandes; antenas serradas, con 11antenómeros; borde anterior del clípeo convexo; labro membranoso emarginado; mandíbulas simples; palpos maxilares de 3 palpómeros, los labiales de 3; tentorio con una fosita. Tórax. Pronoto tan ancho como largo, ligeramente más angosto que los élitros; borde posterior continuo; élitros cortos, ápice romo; alas membranosas con la venación reducida a la vena media, y la célula radial cerrada; primer tarsómero de las patas anteriores con espinas apicales curvadas; uñas simples.

Etimología. Tarsakanthos n. gen., formado por los vocablos griegos tarsus $=$ tobillo y akanthos $=$ espina.

\section{Tarsakanthos minuta n. sp. (Figs. 11-17)}

Diagnosis de la especie tipo. Largo total 2.9. Ancho total 0.4. Cuerpo alargado, pardo oscuro a excepción de antenas, clípeo y patas de color amarillento. Alas membranosas con la venación reducida a la mediana posterior (MP) y con la célula radial (CR) de forma triangular cerrada; las espinas curvas del protarso y la forma triangular del aparato reproductor masculino,separan esta especie de todas las conocidas entre los Penicillophorinae.

Descripción del holotipo macho. Cabeza. Tan larga como ancha a nivel de los ojos (0.5 -0.5), tegumento chagrinado, setífero, gruesamente punteado (Fig. 11); tubérculos antenales prominentes, distancia interantenal 0.02; antenas ligeramente serradas (Fig. 11), de 11 antenómeros, largas, alcanzando el borde posterior del pronoto, primeros 5 antenómeros más largos, la longitud de los antenómeros 4-6 es de 0.29; ojos prominentes, semiesféricos, ocupando 2 tercios de la cabeza, granulosamente facetados, 2 veces más largos que anchos, distancia interocular 0.2; frente ancha, casi tan ancha como el largo del primer antenómero, declivente con el borde anterior recto; clípeo indistinto; borde anterior del labro membranoso convexo; mandíbulas falcadas, simples; último palpómero de los palpos maxilares acuminado, tan largo como el primero, galea angosta; ápice del último palpómero de los palpos labiales romo; tentorio con una fosita en la base de las partes bucales. (Fig. 12). Tórax. Pronoto casi tan largo como ancho (0.50 -0.48), ligeramente más ancho en la mitad anterior, borde anterior cóncavo, el posterior convexo y continuo, tegumento brillante, setífero, rugosa y gruesamente punteado; escutelo espatulado, disco cóncavo, diminutamente punteado y setífero; élitros cortos 

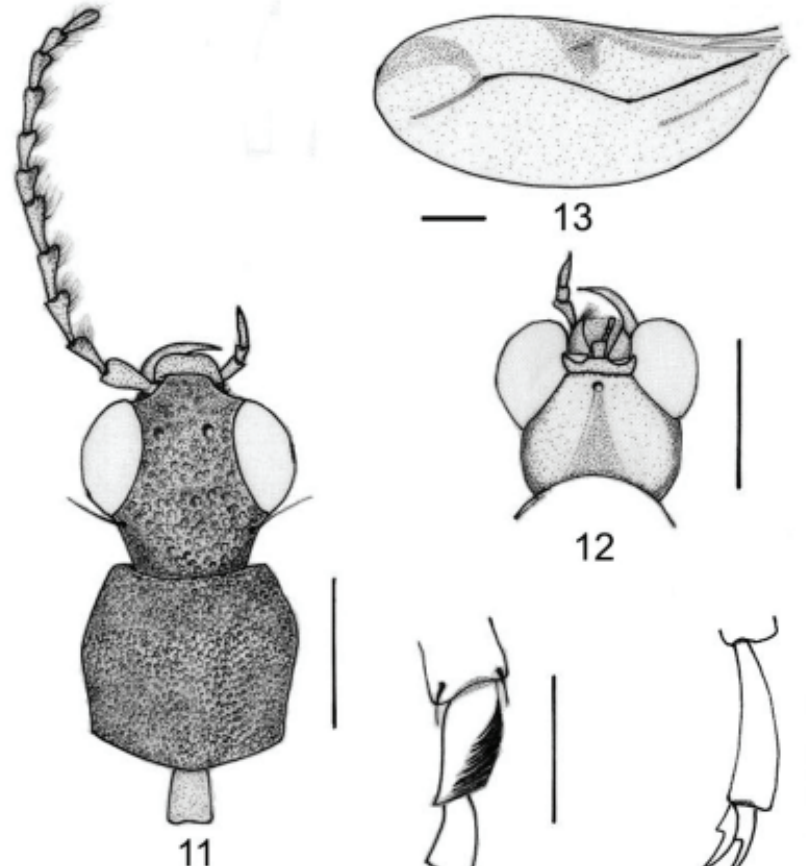

12

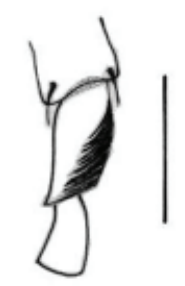

14

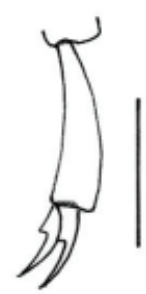

15

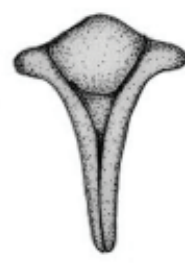

16

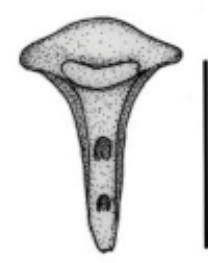

17
Figuras 11-17. Tarsakanthos minuta n. sp. 11, vista dorsal de la cabeza y pronoto; 12, vista ventral cabeza; 13, vista dorsal del ala membranosa izquierda; 14, vista lateral de los primeros tarsómeros del protarso; 15, vista lateral del último tarsómero metatarsal y uñas; 16-17, vista lateral y ventral del edeago. Línea $=0.5 \mathrm{~mm}$.

con el borde posterior acuminado, tegumento chagrinado en su tercio distal, epipleura ancha en su base; alas membranosas (Fig. 13) largas, cubriendo todo el abdomen, venación reducida con vestigios de venas radiales $(\mathrm{R})$, la célula radial (CR) representada por una estructura triangular, la mediana posterior (MP) se une a la radial posterior (RP), se distinguen vestigios de venas cubitales (CU). Patas cortas, tibias con 2 espinas apicales (Fig.14), primer segmento de los tarsos anteriores con un mechón de espinas recurvadas (Fig. 14), primer y segundo tarsómero de las patas anteriores y medias de longitud semejante. Uñas simples. Abdomen. Con 7 ventritos visibles, borde posterior del sexto casi recto, borde posterior del séptimo romo, superficie de los 2 últimos esternitos y pigidio cubiertos con largas y numerosas sedas; edeago (Figs. 1617), de forma triangular, pieza basal abombada, lóbulos laterales casi cubriendo dorsalmente al lóbulo medio, orificio medio casi terminal. Hembra desconocida.

Holotipo macho. Atraído a la luz. México, Oaxaca, Parque Nacional Huatulco, Estación El Sabanal, $15^{\circ}$ 48' 10.7', N; 96 11' 39.4' O, 109 m, trampa de luz 1, 30.05.2005. Cols. Santiago Zaragoza-Caballero, Felipe Noguera, Enrique González, Enrique Ramírez, Lucía Salas. Etimología. El término minuta, por lo pequeño de la especie.

Clave para identificar géneros de Penicillophorinae

1. Primeros 2 segmentos abdominales con largas sedas a los lados; antenas con 10 antenómeros; ápice del primer tarsómero del pro y mesotarso con un peine de 4 o 5 dientes...

1'. Segmentos abdominales sin sedas a los lados; antenas con 11 antenómeros o 12 antenómeros; ápice del primer tarsómero del pro y mesotarso con peine o sin peine. Penicillophorus Paulus

2. Cabeza con una fosita tentorial; antenas con 11 antenómeros.

2. Cabeza con 2 fositas tentoriales; antenas con 11 antenómeros 012 antenór

3. Palpos maxilares con 4 palpómeros; pronoto marcadamente más largo que ancho; primer tarsómero del pro y mesotarso con un peine de 10 dientes en la mitad apical.

3'. Palpos maxilares con 3 palpómeros; pronoto ligeramente más ancho que largo; ápice del primer tarsómero del protarso con una hilera de espinas apicales.....

4. Antenas con 11 antenómeros; palpos maxilares con 3 palpómeros; tarsos simples, sin peines; segundo tarsómero del mesotarso 2 veces más largo que el primero .

4'. Antenas con 12 antenómeros; palpos maxilares con 4 palpómeros; primer tarsómero del pro y mesotarso con un peine ventral a todo lo largo; segundo tarsómero del mesotarso tan largo como el primero.. 


\section{Agradecimientos}

A Felipe Noguera, Enrique González, Enrique Ramírez y Lucía Salas, por su participación en la recolección del material de estudio. A Martín Zurita la composición de las láminas. Al CONACYT y a la CONABIO por el apoyo financiero otorgado bajo el convenio SEMARNAT 2002 CO1-0258.

\section{Literatura citada}

Paulus, H. F. 1975. Penicillophorus ctenotarsus n. gen. et n. sp. Aus Kolumbien, mit einer Beschreinbung einer neuen Tribus Penicilliphorini der Phengodidae (Col. Polyphaga, Cantharoidea). Zeitschrift Arbeitsgemeinschaft Oesterr. Entomololegen (ersehenen Jan. 1975).25:69-80.

Wittmer, W. 1976. Arbeiten zu einer Revision der Familie Phengodidae (Coleoptera). Entomologischen Arbeiten aus dem Museum G. Frey, München 27:415-524.

Wittmer, W. 1981. Zur kenntnis der familia Phengodidae (Coleoptera). Mitteilungen Entomologischen der Entomologischen Gesellschaft Basel NF 31:105-107. 